\title{
COMUNICAÇÃO E INDÚSTRIA CRIATIVA: O PPGCIC COMO UM AMBIENTE PARA A ECONOMIA CRIATIVA
}

\author{
Fabio Frá Fernandes ${ }^{1}$, Alessandro Mateus Felippe ${ }^{2}$ \\ ${ }^{1}$ fabiofernandes@unipampa.edu.br \\ 2allessandro.fpp@gmail.com
}

\section{Resumo}

Este ensaio possui caráter teórico-exploratório, e busca refletir sobre economia criativa e indústria criativa, relacionando esta reflexão à proposta do PPGCIC - Programa de PósGraduação (stricto sensu - modalidade profissional) em Comunicação e Indústria Criativa da Unipampa (campus São Borja), percebendo-o como um ambiente para economia criativa. Ambiente este, onde são desenvolvidas reflexões e aplicações práticas sobre a comunicação como uma indústria criativa ou para a promoção da indústria criativa por meio de técnicas e práticas da comunicação. Com este ensaio, busca-se ainda orientar outras abordagens e ampliar o escopo de discussão acerca da economia criativa.

Palavras-chave: Comunicação. Indústria criativa. Economia Criativa.

\section{COMMUNICATION AND CREATIVE INDUSTRY: THE PPGCIC AS AN ENVIRONMENT FOR THE CREATIVE ECONOMY}

\section{Abstract}

This essay has a theoretical-exploratory nature, and seeks to reflect on creative economy and creative industry, relating this reflection to the proposal of the PPGCIC - Postgraduate Program (Stricto Sensu - professional modality) in Communication and Creative Industry of Unipampa (São Borja campus), perceiving it as an environment for creative economics. This environment, where reflections and practical applications are developed on communication as a creative industry or for promotion from creative industry through communication techniques and practices. With this essay, we also seek to guide other approaches and broaden the scope of discussion about the creative economy.

Keywords: Communication. Creative Industry. Creative Economy.

\section{Introdução}

A proposta deste ensaio é refletir sobre economia criativa e indústria criativa (entendimento, conceituação e produção), relacionando esta reflexão à proposta do PPGCIC Programa de Pós-Graduação (stricto sensu - modalidade profissional) em Comunicação e Indústria Criativa da Universidade Federal do Pampa (campus São Borja), no intuito de percebê-lo como um ambiente para a economia criativa. Ambiente este, onde são desenvolvidas reflexões e aplicações práticas sobre a comunicação como uma indústria criativa ou para a promoção da indústria criativa por meio de técnicas e práticas da comunicação e, assim, constituir possibilidades para ampliar a economia criativa no município de São Borja (RS) e região.

Com caráter teórico-exploratório, este ensaio é constituído de um trabalho de revisão bibliográfica sobre os objetos: economia criativa, indústria criativa e PPGCIC. Sua estrutura é organizada partindo primeiramente, do entendimento e conceituação da economia criativa e da

R. Eletr. do Alto Vale do Itajaí - REAVI, v. 7, n. 11, p. 01-09, dez., 2018 ISSN: 2316-4190, DOI: $10.5965 / 2316419007112018020$ 
indústria criativa nas duas primeiras seções, dialogando com autores comuns à temática. $\mathrm{Na}$ terceira, são apresentados os ganhos econômicos sobre a produção da economia criativa no Brasil com base em pesquisa realizada pela Federação das Indústrias do Estado do Rio de Janeiro (FIRJAN). E, na seção seguinte (quarta), é introduzido o PPGCIC, no exercício percepção sobre ele como um ambiente para a economia criativa.

\section{Entendendo o conceito de economia criativa}

Os estudos e o pragmatismo sobre economia criativa e indústria criativa vêm crescendo vertiginosamente em todo o mundo. No Brasil isso acontece de forma mais alargada na segunda década deste século, como alternativa para as falhas da economia tradicional, da polarização social e da grande desigualdade econômica (DUIESENBERG, 2008) presente em todo o território nacional.

Enquanto a economia tradicional trabalha com a escassez de recursos e como isso é administrado para garantir o acesso das pessoas aos mais variados bens e serviços (GREGORY, 2013), a economia criativa surge para trabalhar com a abundância, visto que a criatividade é um recurso inesgotável (LEITÃO, 2011; REIS, 2008; 2011; CAIADO, 2011; FLORIDA, 2011; DUIESENBERG, 2008; 2009) e inerente a todo ser humano (OSTROWER, 1975; ALENCAR, 1995; SCHEER, 2013) podendo ser, de forma mínima ou máxima, apropriada e aplicada na produção de bens e serviços, conotando diferentes formas de gerar valor sobre essa produção. A criatividade é um ativo que emana da própria formação, da cultura e das raízes dos indivíduos (REIS, 2011). São estas peculiaridades que tornam um bem ou serviço criativo artefato de grande valor econômico. A relação entre o simbólico (pensamento criativo) e o concreto (bens e serviços) é o que vai transmutar essa criatividade em um catalisador de valor econômico (REIS, 2011). Essa transmutação é o que constitui o interesse da economia criativa.

Frequentemente associado ao termo indústria criativa, embora distintos, mas indissociáveis, o termo economia criativa foi utilizado pela primeira vez por John Howkins (2001) no livro "The Creative economy: how people make money from ideas" (FLORIDA, 2011; REIS, 2008; DUIESENBERG, 2009; UNCTAD, 2010). A sistematização de ambos os termos, entretanto, surge alguns anos antes: na Austrália, em 1994 e Inglaterra, em 1997. Em ambas as situações, a ideia central era de caracterizar a emergência da criatividade como insumo para a economia, com foco especial no fomento às atividades culturais.

Economia criativa pode ser definida por atividades que resultam em indivíduos exercitando sua imaginação e a explorando com valor econômico. É resultado dos processos de criação, produção e distribuição de bens e serviços, usando conhecimento, criatividade e capital intelectual como principais insumos produtivos (HOWKINS, 2012). É por meio da criatividade que o mundo contemporâneo é inundado por sons, imagens, símbolos e ideias que geram novos empregos, e ajudam a mitigar a pobreza. A ideia de economia criativa vem não somente para qualificar aspectos econômicos, mas também para inferir no desenvolvimento social, tecnológico e cultural das sociedades de uma forma sustentável (DUIESENBERG, 2009; NEWBIGIN, 2010; UNCTAD, 2010; VALIATI et al, 2017).

O conceito de economia criativa apresenta-se como um marco teórico que se volta para a formulação de estratégias de desenvolvimento, que estão centradas no impacto positivo das indústrias criativas, com o crescimento econômico e com a inovação tecnológica (POTTS; CUNNINGHAM, 2008 apud VALIATI et al, 2017).

Com a economia criativa, conforme refletem a UNCTAD (2010), áreas urbanas são reavivadas, áreas rurais remotas são desenvolvidas, e os recursos ambientais, patrimoniais e culturais de um território são preservados, favorecendo o desenvolvimento econômico. Um dos impactos sociais mais importantes da economia criativa é a geração de empregos. Na cultura, a economia criativa vai materializar valor econômico em artefatos culturais tangíveis e

R. Eletr. do Alto Vale do Itajaí - REAVI, v. 7, n. 11, p. 01-09, dez., 2018 ISSN: 2316-4190, DOI: $10.5965 / 2316419007112018020$ 
intangíveis. É do valor cultural de um território que se dá seu valor econômico. Desse caminho, a economia criativa então favorece o desenvolvimento sustentável, pois reconhece e trabalha para preservar e desenvolver todos estes insumos e, do capital intelectual, promove a obtenção de ativos financeiros que permitem qualificar a vida dos indivíduos, de suas comunidades e territórios.

Vale destacar que, pela economia criativa, ainda são constituídas novas formas de organizações sociais, novos modelos de consumo, sistemas, ambientes, artefatos, serviços, experiências e muitos outros, além da capacidade de reinventar as formas de agregar valor a partir de exercícios da imaginação criativa (STAHNKE, 2017; BERTONI; MOURA, 2016).

\section{Indústrias Criativas: o âmago de uma economia baseada na criatividade}

No âmago da economia criativa estão as indústrias criativas. A indústria criativa se apresenta como ciclos de criação, produção e distribuição de bens e serviços que tem na criatividade o insumo primeiro de sua constituição. Essa produção vem dotada com conteúdo criativo, com valor cultural e com objetivos de mercado (DUISENBERG, 2009). Ou seja, para uma atividade pertencer ao escopo da indústria criativa, sua produção deve estar carregada com valores culturais de seu criador e de seu entorno, ser oriunda de exercícios de criatividade, imaginação e inventividade, e sua circulação e consumo devem, de uma forma ou outra, produzir algum tipo de retorno social convertido em valor econômico para o indivíduo criativo e sua comunidade.

O termo indústria criativa está intimamente vinculado a diversas disciplinas, como a administração, o desenvolvimento, a sociologia, antropologia, comunicação, entre outros. Ao se revisar as definições mais conhecidas e creditadas sobre indústria criativa, quatro elementos aparecem como base de sua constituição e reconhecimento. Esse quadrante é formado pela criatividade, pela cultura moldada em artefatos tangíveis, pelo valor econômico agregado aos artefatos culturais e na convergência entre arte, negócio e tecnologia (FERNANDES; SILVA, 2017; BENDASSOLLI et al, 2009). Na indústria criativa a cultura é tratada na forma de objetos, e seu valor é agregado pelos significados que estes objetos podem vir a ter, representar ou compartilhar. São esses significados que a indústria criativa transforma em propriedade intelectual e, portanto, passam a possuir valor econômico (economia criativa).

A ideia de indústria criativa emerge da aproximação das indústrias culturais com as artes criativas. Uma aproximação que permite melhor compreensão do papel contemporâneo da cultura em novos modelos de crescimento econômico. Reside aqui a cultura e a criatividade sendo referenciadas como fatores competitivos e estratégicos para todas e quaisquer atividades econômicas de bens e serviços (MATEUS, 2010). Assim, fica claro que a criatividade, na indústria criativa (e economia criativa) é o insumo primeiro, enquanto o conteúdo gerado (simbólico e cultural; material e imaterial) é o produto da atividade-fim dessa indústria (MARTINS, 2017).

Assim, alguns conceitos podem ser percebidos para a indústria criativa, harmonizando os elementos de sua constituição - criatividade, propriedade intelectual, valor cultural e de mercado (grifo nosso). Para a Conferência das Nações Unidas para o Comércio e o Desenvolvimento (UNCTAD, 2010), a indústria criativa é compreendida por ciclos de criação, produção e distribuição de produtos e serviços que utilizam criatividade e capital intelectual como insumos primários. São constituintes de atividades baseadas no conhecimento, focada nas artes que, potencialmente, deverão gerar receitas de vendas e direitos de propriedade intelectual. Os bens gerados são tangíveis e os serviços intangíveis. A indústria criativa vai se posicionar no cruzamento entre os setores artísticos, de serviços e industriais, e assim constitui-se em um novo setor dinâmico no comércio mundial.

R. Eletr. do Alto Vale do Itajaí - REAVI, v. 7, n. 11, p. 01-09, dez., 2018 ISSN: 2316-4190, DOI: $10.5965 / 2316419007112018020$ 
John Howkins (2012) entende indústria criativa como a indústria onde o trabalho intelectual é preponderante e o resultado alcançado com isso é a propriedade intelectual. Jambeiro e Ferreira (2012) vão considerar a indústria criativa como aquela que produz bens e serviços reconhecidos por sua riqueza social, cultural e econômica tendo, também, como insumo básico a criatividade, ou seja, propriedades artísticas, intelectuais e mentais. Throsby (2018) afirma que é o valor cultural (ou conteúdo cultural) agregado a produção das indústrias culturais (criativas) que conotam sua distinção sobre a indústria tradicional.

Já o Departamento de Cultura, Mídia e Esporte do Reino Unido (DCMS, 2018), trata a indústria criativa pelas atividades nascidas do pensamento criativo, de competências e do talento individual, com potencial para a criação de trabalho e riqueza por meio da geração e exploração de propriedade intelectual.

As indústrias criativas têm então, como base principal, indivíduos com capacidades criativas e artísticas em aliança com gestores e profissionais da área tecnológica, que fazem produtos vendáveis, cujo valor econômico vai residir nas suas propriedades culturais ou intelectuais.

\section{A setorização e a cadeia de produção da economia criativa no Brasil}

Muitas são as formas de classificação das indústrias criativas e também na forma como sua produção é quantificada. Sobre a classificação, tem-se a exemplo a organização setorial do Departamento de Cultura Mídia e Esportes do Reino Unido (DCMS, 2018), dos círculos concêntricos do Throsby (2018), o modelo da Organização Mundial de Propriedade Intelectual (WIPO, 2015), composto da Conferência das Nações Unidas sobre Comércio e Desenvolvimento (UNCTAD, 2010), setorização do Ministério da Cultura do Brasil (MinC, 2012), da Federação das Indústrias do Rio de Janeiro (FIRJAN, 2016), entre outros.

O principal elemento de diferenciação na forma como são classificadas e organizadas as indústrias criativas nesses modelos é o uso da criatividade. Cada um desses modelos realiza a leitura das atividades criativas e culturais a partir da intensidade da criatividade na produção de bens e serviços. Alguns setores são mais criativos, figurando no centro ou núcleo da cadeia de produção da economia criativa, outros, atuariam de forma relacionada ou como apoio ao centro criativo das indústrias criativas. Também são levados em consideração questões como a propriedade intelectual, e os ciclos de produção, distribuição e consumo destes bens e serviços (VALIATI et al, 2017; NOBRE, 2015).

Por exemplo, no modelo do DCMS (2018) as atividades nucleares são relacionadas a publicidade e marketing, arquitetura, artesanato, design, filme, TI, área editorial, área da museologia e patrimonial, música e artes. Já a UNCTAD (2010), congrega o núcleo criativo das indústrias criativas em 04 grandes grupos, sendo eles: patrimônio, artes, mídia e criações funcionais. Grupos estes, ainda divididos em 09 subgrupos: expressões culturais tradicionais, locais culturais, artes visuais, artes cênicas, editoras e mídia impressa, audiovisual, design, novas mídias e serviços criativos.

No cenário brasileiro, a FIRJAN (2016), setoriza a indústria criativa em três grupos, sendo o primeiro, o núcleo criativo formado pelos profissionais e pela produção nas áreas de consumo (design, arquitetura, moda e publicidade), mídias (editorial e audiovisual), cultura (patrimônio e artes, música, artes cênicas e expressões culturais) e Tecnologia (P\&D, biotecnologia e TIC). No segundo grupo, figuram os profissionais e organizações que dão suporte a indústria criativa. Este grupo é formado pelos serviços e indústrias relacionadas ao núcleo criativo. Já no terceiro grupo, estão as atividades de apoio, as quais vão fornecer indiretamente bens e serviços à indústria criativa (FIRJAN, 2016; FERNANDES; SILVA, 2017).

R. Eletr. do Alto Vale do Itajaí - REAVI, v. 7, n. 11, p. 01-09, dez., 2018 ISSN: 2316-4190, DOI: $10.5965 / 2316419007112018020$ 
Ao quantificar a produção da economia criativa no Brasil, tem-se um cenário promissor ao perceber um crescimento médio do PIB de 2,56 por cento, o que significa mais de R 155 bilhões gerados pelos setores criativos. No mesmo período, o trabalho formal na indústria criativa no país fechou uma média de 850 mil trabalhadores. As áreas criativas com melhor desempenho são: consumo (design, arquitetura, moda e publicidade), com 44,2 por cento, e Tecnologia (P\&D, biotecnologia e TIC) com 36,8 por cento. Os Estados de São Paulo, Rio de Janeiro e Distrito Federal lideram os índices de regiões com maior desenvolvimento da economia criativa, seguido pelos Estados de Santa Catarina e Rio Grande do Sul (FIRJAN, 2016).

\section{PPGCIC: ambiente para a economia criativa}

Da breve contextualização apresentada nas seções anteriores, é colocado em questão o PPGCIC - Programa de Pós-Graduação em Comunicação e Indústria Criativa, tentando percebê-lo como um ambiente para a economia criativa. Esta seção é iniciada compreendendo sua configuração e sua articulação com as abordagens apresentadas anteriormente. O Programa de Pós-Graduação em Comunicação e Indústria Criativa é um mestrado profissional, implantado no campus da Unipampa - Universidade Federal do Pampa no município de São Borja em novembro de 2016, que se constitui para problematizar a teoria e a prática da comunicação no âmbito profissional da economia criativa e da indústria criativa.

Seguindo os preceitos da estruturação da Unipampa, que busca desenvolver a metade sul do Estado do Rio Grande do Sul, por meio do ensino superior, bem como contribuir com a integração e desenvolvimento da região de fronteira do Brasil com a Argentina e o Uruguai (UNIPAMPA, 2013), o PPGCIC se constitui como um ambiente para pensar alternativas à preservação, valorização e desenvolvimento de setores importantes da economia criativa com presença abundante em São Borja e região. Muitos deles, por diversos motivos, estão desassistidos pela sociedade civil, pela iniciativa privada e pelo poder público. Da mesma forma, se apresenta como o primeiro programa de pós-graduação em comunicação e indústria criativa localizado fora das regiões metropolitanas do país.

Sua constituição contribui também para a especialização de profissionais de relações públicas, publicidade e propaganda, jornalismo, design, arquitetura, moda, editoração, cinema, artes entre outros, oriundos de áreas correlatas e afins às Ciências Sociais Aplicadas que atuam nessa região e encontram dificuldades para se aperfeiçoarem nessa temática.

O Programa objetiva reconhecer a comunicação no âmbito profissional da indústria criativa, organizando um ambiente propício para capacitar o pesquisador/profissional a perceber a comunicação como um processo criativo ou a comunicação enquanto estratégia, técnica e instrumento para o processo criativo. Busca atualizar esse mesmo pesquisador/profissional, inserido ou não no mercado, para o desenvolvimento teórico-prático da comunicação e da indústria criativa. E propulsionar a indústria criativa na metade sul do Estado do Rio Grande do Sul, contribuindo para a consolidação do campo da indústria criativa na pós-graduação em comunicação, de modo a articular a interdisciplinaridade da área e promover ainda articulação das políticas educacionais com as políticas culturais (PPGCIC, 2018).

O Programa possui duas linhas de pesquisa - comunicação como e para a indústria criativa. A primeira linha percebe a comunicação como indústria criativa, ou seja, um produto da indústria criativa, precisando a comunicação produzir bens e serviços que contribuam com a riqueza social, cultural e econômica, ela é a atividade criativa em si, representada pela produção, a exemplo, da publicidade, relações públicas, da mídia, do audiovisual, entre tantos outros. Já na segunda linha, a comunicação trabalha para a indústria criativa, significando um processo de comunicação para a indústria criativa. Munida por seus profissionais (relações-

R. Eletr. do Alto Vale do Itajaí - REAVI, v. 7, n. 11, p. 01-09, dez., 2018 ISSN: 2316-4190, DOI: $10.5965 / 2316419007112018020$ 
públicas, publicitários, jornalistas) e de seus aparelhos comunicacionais, a comunicação vai trabalhar para promover, consolidar e valorizar a economia criativa e suas indústrias (FEIL; GUINDANI, 2018).

Ao pesquisador/profissional que participa do Programa, cabe o desenvolvimento de dois produtos, sendo um de aplicação prática - projeto de PD\&I - Pesquisa, Desenvolvimento e Inovação -, e outro de cunho reflexivo, constituído na forma de dissertação. A PD\&I, no PPGCIC, se materializa em dois momentos, sendo: o primeiro, no processo de planejamento de um processo ou produto, com ampla revisão da literatura e aferição de sua relevância social, regional; e o segundo configura-se na execução desse projeto, quando as ideias inovadoras resultantes da pesquisa e do desenvolvimento são aplicadas pragmaticamente (SILVA, 2018), devendo gerar retorno sociocultural e socioeconômico. Ou seja, a consecução de um produto de comunicação para a linha comunicação como indústria criativa e um processo de comunicação na linha de comunicação para a indústria criativa.

São exemplos de produtos e processos de comunicação e indústria criativa, que podem ser desenvolvidos pelos discentes e docentes do Programa: ações de comunicação integrada; produção audiovisual institucional em mídia eletrônica e digital; produção gráfica e editorial; projetos culturais; protótipo de mapeamento de manifestações e equipamentos criativos e culturais; marketing de produtos e serviços criativos e culturais; campanhas de relações públicas; produção de eventos; projetos de acessibilidade cultural; produção em fotografia e memória; ações e produtos em apoio ao patrimônio e/ou ao turismo cultural, produção de moda, desenvolvimento de softwares, produção em design, fotografia, entre outros (PPGCIC, 2018).

A proposta da PD\&I no PPGCIC vai ao encontro do que a CAPES compreende e espera de um Mestrado Profissional, que precisa dar conta de qualificar seus discentes tanto como cientistas, quanto como profissionais. Onde eles deverão ser capazes de solucionar problemas (ou saber fazer) a partir do conhecimento científico. E fornecendo retornos imediatos às comunidades das quais fazem partem.

Da compreensão do que é o Programa, o mesmo é posicionado neste ensaio enquanto ambiente para economia criativa, partindo primeiro dos seus dois objetos de intervenção - a comunicação e a indústria criativa -, estes como insumo principal para a reflexão e proposição de teorias e metodologias que auxiliem o desenvolvimento da economia criativa, a partir da transversalidade da comunicação. E, segundo, ao ler o Programa sob a luz da cadeia produtiva da indústria criativa no Brasil formulado pela FIRJAN.

Ao recuperar a cadeia produtiva da indústria criativa da FIRJAN (2016) para situar seus três grupos, sendo o primeiro, o núcleo criativo formado pelos profissionais e pela produção nas áreas de consumo (design, arquitetura, moda e publicidade), mídias (editorial e audiovisual), cultura (patrimônio e artes, música, artes cênicas e expressões culturais) e Tecnologia (P\&D, biotecnologia e TIC). O segundo, composto pelos profissionais e organizações que dão suporte a indústria criativa. E o terceiro, pelas atividades de apoio, as quais vão fornecer indiretamente bens e serviços à indústria criativa. É possível perceber a presença da comunicação nos três grupos da cadeia de produção, sendo no primeiro a comunicação entendida como uma indústria criativa em si e no segundo e terceiro, pelas atividades prestadas em apoio às atividades nucleares da indústria criativa. Entendemos assim, que a produção intelectual e técnica dos discentes e docentes do PPGCIC, materializado em produtos ou processos de comunicação e indústria criativa, se enquadram nessa categorização, podendo ela vir a ser contabilizada no panorama da economia criativa do país, em especial sobre o Estado do Rio Grande do Sul.

Os setores da economia criativa onde a comunicação atua direta e indiretamente no Brasil, segundo a FIRJAN (2016), são os que mais geraram emprego e renda em seu último mapeamento. Somente na área de consumo e mídia, trabalham mais de 220 mil pessoas. Somando isso a área de P\&D (164,3 mil) e a área de TIC (120,6 mil), a comunicação, apropriada

R. Eletr. do Alto Vale do Itajaí - REAVI, v. 7, n. 11, p. 01-09, dez., 2018 ISSN: 2316-4190, DOI: $10.5965 / 2316419007112018020$ 
da tecnologia, da informação, da pesquisa e do desenvolvimento, ocupa um terço dos postos de trabalho na economia criativa no país. De acordo com a Federação, de 2013 a 2015, os segmentos da publicidade, do design, das expressões culturais, editorial, em especial a P\&D e a biotecnologia, foram os que mais se destacaram na economia criativa brasileira, gerando em conjunto 2,64 por cento do PIB (FIRJAN, 2016).

Assim, do entendimento de Richard Florida (2011) que reconhece as universidades como espaços para a criatividade, quando estas utilizam do conhecimento e do capital intelectual, para produzirem bens e serviços com alto valor cultural e criativo, gerando retornos sociais e econômicos para os territórios onde estão inseridas. Um Programa de Pós-Graduação, portanto, pode ser percebido como um espaço, um ambiente de produção, distribuição e circulação de bens e serviços criativos.

No caso específico do PPGCIC, um mestrado profissional que tem na indústria criativa estreita aproximação com a comunicação. Capacita e forma pesquisadores/profissionais para ampla leitura do mercado e academia relacionados aos seus dois objetos de intervenção. Produz produtos e processos (bens e serviços) com valor cultural, propriedade intelectual, gerando impactos sociais, culturais e econômicos (conforme dialogado pelos autores nas seções iniciais) e ainda se aproxima de profissionais, empresas e organizações como forma de desenvolvimento local e regional, pode e deve ser compreendido como um ambiente de grande relevância para a economia criativa.

\section{Considerações Finais}

Neste ensaio é proposto refletir brevemente sobre o entendimento, conceituação e produção da economia criativa e da indústria criativa e, dessa articulação, refletir também sobre o PPGCIC - Programa de Pós-Graduação em Comunicação e Indústria Criativa da Unipampa, campus São Borja, com objetivo de percebê-lo como um ambiente para economia criativa.

Conforme diálogo entre os autores, a economia criativa é um campo emergente, novo, mas com tendências bem sólidas, tanto no Brasil, quanto em outros países. A economia criativa esta possibilitando novas e renovadas formas de produção, onde o valor está no conhecimento, na criatividade e na inovação, e não mais no processo ou produto em si. Os ciclos de produção, distribuição e consumo da indústria criativa é o que faz girar a matriz da economia criativa. Muitos são os setores e os profissionais envolvidos nesse processo, em diversos espaços e ambientes. Alguns, estando diretamente envolvidos na produção com seu capital intelectual, outros, atuando de forma relacionada ou de apoio. É a economia criativa e a indústria criativa, campos férteis para pesquisas e intervenções.

Sobre isso, destaca-se o PPGCIC. Conforme apresentado anteriormente, é um Programa de Pós-Graduação, alicerçado pelo campo da Comunicação e, disso, realiza a leitura do fenômeno da indústria criativa. É constituído como um ambiente físico, em uma Universidade, e de forma laboratorial, desenvolve pesquisa, desenvolvimento e inovação na forma de produtos e processos nos diversos setores da indústria criativa, em especial sobre a comunicação.

De acordo com dados do Programa, atualmente, dezesseis discentes (pesquisadores/profissionais) regulares, divididos igualmente em cada uma de suas duas linhas de pesquisa (comunicação como/para indústria criativa) estão realizando projetos de PD\&I nos setores da museologia, urbanização, tecnologia, sistemas de informação, educação e mídia. Oito concluíram no primeiro semestre de 2018, já iniciando sua segunda produção, a dissertação e, os outros oito, estão em fase de execução.

É dessa produção que é entendido o PPGCIC como um ambiente para economia criativa. Primeiro, por ser ele um espaço para a construção do conhecimento sobre economia e indústria criativa, sobre comunicação, sobre política e afins; segundo pela compreensão da comunicação no escopo da economia criativa; terceiro pela formação e capacitação de

R. Eletr. do Alto Vale do Itajaí - REAVI, v. 7, n. 11, p. 01-09, dez., 2018 ISSN: 2316-4190, DOI: $10.5965 / 2316419007112018020$ 
pesquisadores/profissionais; e quarto, pela geração de produtos e processos em comunicação e indústria criativa com foco no desenvolvimento social, cultural e econômico de São Borja e região. Ou seja, um ambiente multidimensional e de múltiplas práticas.

Desta articulação, entende-se o cumprimento da proposta deste ensaio. Este texto não se apresenta como um campo fechado, mas como um primeiro olhar sobre o reconhecimento de um programa de pós-graduação como um ambiente para economia criativa. Espera-se que os argumentos aqui apresentados, fatos e dados, sirvam para orientar outras abordagens e ampliar o escopo de discussão acerca da economia criativa.

\section{Referências}

ALENCAR, Eunice Lima Soriano. Desenvolvendo a criatividade nas organizações: o desafio da inovação. Revista de Administração de Empresas, São Paulo, v.35. n. 6, p. 6 -11, nov./dez. 1995.

BENDASSOLLI, Pedro F. et al. Indústrias Criativas: definição, limites e possibilidades. São Paulo: 2009.

BERTOLINI, Cristopher; MOURA, Heloisa. Economia criativa, política de inovação e o papel do design. In: PINHEIRO, Cristiano Max Pereira; BARTH, Maurício. Indústrias Criativas. Novo Hamburgo: Feevale, 2016.

CAIADO, A. S. C. (Coord.). Economia Criativa na cidade de São Paulo: Diagnóstico e Potencialidade. São Paulo: FUNDAP, 2011.

COORDENAÇÃO De APERFEIÇOAMENTO DE PESSOAL DE NÍVEL SUPERIOR (CAPES). Mestrado Profissional: o que é? Disponível em: $<\mathrm{http}$ :/capes.gov.br/avaliacao/sobre-a-avaliacao/mestrado-profissional-o-que-e >. Acesso em: 30 ago. 2018.

CONFERÊNCIA DAS NAÇÕES UNIDAS PARA O COMÉRCIO E DESENVOLVIMENTO (UNCTAD). Relatório das Atividades Criativas: economia criativa, uma opção de desenvolvimento viável. UNCTAD: 2010.

DCMS: Department for Culture, Media and Sport. Creative Industries economics estimate, 2016. Disponível em: $<$ https://www.gov.uk/government/organisations/department-for-digitalculture-media-sport>. Acesso em: 05 ago. 2018.

DUISENBERG, Edna dos Santos. Economia Criativa: uma opção de desenvolvimento viável? In: REIS, Ana Carla Fonseca. (Org.). Economia Criativa como estratégia de desenvolvimento: uma visão dos países em desenvolvimento. São Paulo: Itaú Cultural, 2008.

DUISENBERG, Edna dos Santos. A economia criativa e a indústria cinematográfica na sociedade contemporânea. In: MELEIRO, Alessandra. (Org.). Cinema e Economia Política. São Paulo: Escrituras Editora, 2009.

FEIL, Gabriel Sausen; GUINDANI, Joel Felipe. Comunicação como e Comunicação para a Indústria Criativa. In: GUINDANI, Joel Felipe; SILVA, Marcela Guimarães e. Comunicação e Indústria Criativa: políticas, teorias e estratégias. Jaguarão, RS: CLAEC, 2018.

R. Eletr. do Alto Vale do Itajaí - REAVI, v. 7, n. 11, p. 01-09, dez., 2018 ISSN: 2316-4190, DOI: $10.5965 / 2316419007112018020$ 
FERNANDES, Fabio Frá; SILVA, Marcela Guimarães e. A ampliação da universidade: de espaço de ensino para espaço de criatividade. In: SILVA, Marcela Guimarães e; COUTINHO, Renata Corrêa. Processos e práticas nas atividades criativas e culturais: reflexões e interfaces da comunicação e da indústria criativa. Santiago: Oliveira Books, 2017.

FIRJAN. Mapeamento da Indústria Criativa no Brasil. São Paulo: 2016.

FLORIDA, Richard. A Ascenção da Classe Criativa. Porto Alegre, RS: L\&PM, 2011.

GREGORY, Markiw N. Introdução à economia. São Paulo: Cengage Learning, 2013.

HOWKINS, John. Economia Criativa: como ganhar dinheiro com ideias criativas. 1. ed. São Paulo, SP: M.BOOKS, 2012.

LEITÃO, C. Plano da Secretaria da Economia Criativa: políticas, diretrizes e ações 20112014.

JAMBEIRO, Othon; FERREIRA, Fábio. Compreendendo as Indústrias Criativas de Mídia: contribuições da economia política da comunicação. Revista Comunicação Midiática, v.7, n.3, p.178-194, set./dez. 2012.

MARTINS, Tiago Costa. O 'lugar' das relações públicas na indústria criativa. In: SILVA, Marcela Guimarães e; COUTINHO, Renata Corrêa. Processos e práticas nas atividades criativas e culturais: reflexões e interfaces da comunicação e da indústria criativa. Santiago: Oliveira Books, 2017.

MATEUS, Augusto et al. O sector cultural e criativo em Portugal. AMAS de Consultores, Ed. O Sector Cultural e Criativo em Portugal, 2010.

NOBRE, Guilherme Fráguas. A economia criativa e o valor potencial da Escola de Comunicações e Artes. Organicom - Revista Brasileira de Comunicação Organizacional e Relações públicas, São Paulo, ECA-USP, a.12, n.23, p. 180-190, 2015.

OSTROWER, Fayga. Criatividade e Processos de Criação. Rio de Janeiro: Editora Vozes, 1977.

PROGRAMA DE PÓS-GRADUAÇÃO EM COMUNICAÇÃO E INDÚSTRIA CRIATIVA (PPGCCIC). Sobre O PPGCIC. Disponível em: < http://cursos.unipampa.edu.br/cursos/ppgcic/>. Acesso em: 07 de agosto de 2018.

REIS, Ana Carla Fonseca. Economia da cultura e desenvolvimento sustentável: o caleidoscópio da cultura. Barueri: Manole, 2007.

REIS, Ana Carla Fonseca (Org.). Economia Criativa como estratégia de desenvolvimento: uma visão dos países em desenvolvimento. São Paulo: Itaú Cultural, 2008.

REIS, Ana Carla Fonseca. Cidades Criativas: análise de um conceito em formação e da pertinência de sua aplicação à cidade de São Paulo. 2011. Tese de Doutorado (Arquitetura e Urbanismo) - USP, São Paulo, SP. 
SCHEER, Sérgio. Criatividade e Inovação: potencializadores da economia criativa. In: MORAES, Alexandre Donizete Lopes de (et. al.). Economia Criativa: conhecimento e empreendedorismo para uma sociedade sustentável. Curitiba: UFPR, 2013. P. 72-86.

SILVA, Marcela Guimarães e. Pesquisa, Desenvolvimento \& Inovação em comunicação e indústria criativa: noções introdutórias. In: GUINDANI, Joel Felipe; SILVA, Marcela Guimarães e. Comunicação e Indústria Criativa: políticas, teorias e estratégias. Jaguarão, RS: CLAEC, 2018.

STAHNKE, Fernando Rafael. 3 dimensões da economia criativa: estudo e proposta de um painel de indicadores. Dissertação (mestrado em Indústria Criativa). FEEVALE, Novo Hamburgo, 2017.

THROSBY, David. The concentric circles model of the cultural industries. Cultural Trends, v. 17, n. 3, p. 147-164, set. 2008.

UNIVERSIDADE FEDERAL DO PAMPA (UNIPAMPA). Plano de Desenvolvimento Institucional 2014-2018. Bagé, Unipampa, 2013. Disponível em: < http://porteiras.s.unipampa.edu.br/pdi/files/2015/08/PDI_Unipampa_v19_.compressed.pdf $>$.

Acesso em 30 ago. 2017.

VALIATI et al. Economia criativa e da cultura: conceitos, modelos teóricos e estratégias metodológicas. In: VALIATI, Leandro; FIALHO, Letícia do Nascimento. Atlas econômico da cultura brasileira: metodologia I. Porto Alegre: Editora UFRGS/CEGOV, 2017. 